Int. J. Electrochem. Sci., 15 (2020) 10979 - 10993

International Journal of

ELECTROCHEMICAL

SCIENCE

WWW.electrochemsci.org

\title{
Porous Carbon Derived from Nutshell as Electrode Materials for Supercapacitors
}

\author{
Yu-Long Xie*, Qian-Ni Guo, Cuo-Ji Ben, Li-Fang Guo
}

Key Laboratory of Resource Chemistry and Eco-environmental Protection in Tibetan Plateau of State Ethnic Affairs Commission, School of Chemistry and Chemical Engineering, Qinghai Nationalities University, Xining, Qinghai, 810007, China

*E-mail: yulongxie2012@,126.com

doi: $10.20964 / 2020.11 .35$

Received: 9 June 2020 / Accepted: 9 September 2020 / Published: 30 September 2020

The porous activated carbons derived from walnut epicarp is utilized as activated carbon electrodes for supercapacitors. The field emission scanning microscope and transmission electron microscopy tests demonstrate that the nutshell porous activated carbons (WEPACs) treated with $\mathrm{ZnCl}_{2}$ can produce a large number of mesopores. As an electrode material for supercapacitor, the WEPACs possess high specific capacitance of $235 \mathrm{~F} \cdot \mathrm{g}^{-1}$ at a current density of $0.5 \mathrm{~A} \cdot \mathrm{g}^{-1}$ in three-electrode systems. As assembled WEPACs//WEPACs symmetric supercapacitor device exhibits specific energies of 17.1 $\mathrm{Wh} \cdot \mathrm{kg}^{-1}$ at a power density of $299 \mathrm{~W} \cdot \mathrm{kg}^{-1}$ and in the voltage range of $0-1.2 \mathrm{~V}$. Moreover, it retaineds about $90.3 \%$ of the initial capacitance after 5000 charge-discharge cycles, indicating an excellent cyclic stability.

Keywords: Porous carbon, Supercapacitors, High energy density

\section{FULL TEXT}

(C) 2020 The Authors. Published by ESG (www.electrochemsci.org). This article is an open access article distributed under the terms and conditions of the Creative Commons Attribution license (http://creativecommons.org/licenses/by/4.0/). 